\title{
Assessing capacity of health facilities to provide routine maternal and newborn care in low-income settings: what proportions are ready to provide good- quality care, and what proportions of women receive it?
}

Keith Tomlin ${ }^{*}$, Della Berhanu², Meenakshi Gautham³ ${ }^{3}$ Nasir Umar², Joanna Schellenberg ${ }^{2}$, Deepthi Wickremasinghe ${ }^{2^{\wedge}}$ and Tanya Marchant ${ }^{2}$

\begin{abstract}
Background: Good quality maternal and newborn care at primary health facilities is essential, but in settings with high maternal and newborn mortality the evidence for the protective effect of facility delivery is inconsistent. We surveyed samples of health facilities in three settings with high maternal mortality to assess their readiness to provide routine maternal and newborn care, and proportions of women using facilities that were ready to offer good quality care. Surveys were conducted in 2012 and 2015 to assess changes over time.
\end{abstract}

Methods: Surveys were conducted in Ethiopia, the Indian state of Uttar Pradesh and Gombe State in North-Eastern Nigeria. At each facility the staffing, infrastructure and commodities were quantified. These formed components of four "signal functions" that described aspects of routine maternal and newborn care. A facility was considered ready to perform a signal function if all the required components were present. Readiness to perform all four signal functions classed a facility as ready to provide good quality routine care. From facility registers we counted deliveries and calculated the proportions of women delivering in facilities ready to offer good quality routine care.

Results: In Ethiopia the proportion of deliveries in facilities classed as ready to offer good quality routine care rose from 40\% (95\% confidence interval (Cl) 26-57) in 2012 to 43\% (95\% Cl 31-56) in 2015. In Uttar Pradesh these estimates were 4\% (95\% Cl 1-24) in 2012 and 39\% (95\% Cl 25-55) in 2015, while in Nigeria they were 25\% (95\% Cl 6-66) in 2012 and zero in 2015. Improved facility readiness in Ethiopia and Uttar Pradesh arose from increased supplies of commodities, while in Nigeria facility readiness fell due to depleted commodity supplies and fewer Skilled Birth Attendants.

(Continued on next page)

\footnotetext{
* Correspondence: keith.tomlin@lshtm.ac.uk

Deepthi Wickremasinghe is deceased.

${ }^{1}$ Faculty of Epidemiology and Population Health, London School of Hygiene

\& Tropical Medicine, Keppel Street, London WC1E 7HT, UK

Full list of author information is available at the end of the article
}

(c) The Author(s). 2020 Open Access This article is licensed under a Creative Commons Attribution 4.0 International License, which permits use, sharing, adaptation, distribution and reproduction in any medium or format, as long as you give appropriate credit to the original author(s) and the source, provide a link to the Creative Commons licence, and indicate if changes were made. The images or other third party material in this article are included in the article's Creative Commons licence, unless indicated otherwise in a credit line to the material. If material is not included in the article's Creative Commons licence and your intended use is not permitted by statutory regulation or exceeds the permitted use, you will need to obtain permission directly from the copyright holder. To view a copy of this licence, visit http://creativecommons.org/licenses/by/4.0/ The Creative Commons Public Domain Dedication waiver (http://creativecommons.org/publicdomain/zero/1.0/) applies to the data made available in this article, unless otherwise stated in a credit line to the data. 
(Continued from previous page)

Conclusions: This study quantified the readiness of health facilities to offer good quality routine maternal and newborn care, and may help explain inconsistent outcomes of facility care in some settings. Signal function methodology can provide a rapid and inexpensive measure of such facility readiness. Incorporating data on facility deliveries and repeating the analyses highlighted adjustments that could have greatest impact upon routine maternal and newborn care.

Keywords: Maternal and newborn care, Primary health facilities, Facility delivery, Signal functions, Quality of care, Ethiopia, India, Nigeria, Sub-Saharan Africa

\section{Background}

Maternal mortality - the death of women while pregnant or within 42 days of the end of pregnancy - is estimated to have declined globally by $43 \%$ between 1990 and 2015 [1]. Nevertheless, in 2015 an estimated 303, 000 women died as a result of complications during pregnancy and childbirth, and the global decline masks substantial regional variation: $88 \%$ of all maternal deaths in 2015 occurred in sub-Saharan Africa and Southern Asia [1]. Neonatal mortality - the death of infants within the first 28 days after birth - is also estimated to have declined globally between 1990 and 2017 [2], but 2.5 million newborns are estimated to have died in 2017 and the same regional disparities present themselves, with sub-Saharan Africa and Southern Asia having among the highest neonatal mortality rates [2].

The most widely accepted strategy for reducing maternal and newborn mortality is to encourage women to give birth in a health facility rather than at home [3, 4]. Health facilities which offer maternal and newborn care are more likely to provide infection control and - ideally - are staffed by Skilled Birth Attendants (SBAs). These are doctors, nurses or midwives who are trained to monitor the progress of labour and delivery, to offer basic medical intervention should obstetric complications arise, and to refer women or newborns to more advanced care if this is needed and available. SBAs have been described as the most important intervention in reducing maternal and newborn deaths $[5,6]$, and increasing the proportion of births at which an SBA is present is a key component of the 2016-2030 Global Strategy for Women's, Children's and Adolescents' Health [7]. In many settings SBAs work exclusively from within health facilities in order to have access to the infrastructure, equipment and medication necessary to provide the most effective care [8].

Between 2000 and 2018 the global proportion of women who gave birth in a health facility is estimated to have risen from 52 to $76 \%$ [9] and this increase is thought to have made a significant contribution to the estimated global declines in maternal and neonatal mortality over the same period. However, in settings where the number of maternal deaths per 100,000 live births is high $(\geq 300)[10]$ the evidence for the protective effect of facility birth is inconsistent [11-15]. This suggests that women in these settings may be attending health facilities but the quality of the service is insufficient to provide the health protection they need. Concern over the poor quality of facility care has also lead to some women avoiding health facilities altogether [8].

Common definitions of the quality of health care have focused upon six core elements: good-quality care should be safe, effective, timely, efficient, equitable and people-centred [16]. Fulfilling these core elements within health facilities is dependent upon a wide range of inputs, and if the quality of care is to be quantified then relevant and consistent measurement of these inputs needs to be applied.

One approach to assessing the quality of maternal and newborn care is the use of "signal functions". These describe specific actions that should be taken in response to events that can arise during labour and delivery, and were initially devised in relation to obstetric complications. For example, a health facility should respond to a woman suffering a ruptured uterus by performing three signal functions - surgery, a blood transfusion and administration of parenteral antibiotics [17]. Each of these require a minimum set of "components" to be present for the facility to carry it out, in the form of professional expertise, infrastructure, and medical equipment and commodities. To be considered ready to perform a signal function a health facility would need to provide all of the components that it would require.

Signal functions have been developed that correspond to a range of obstetric emergencies [17] and Gabrysh and colleagues have extended this methodology by developing six signal functions that can be applied to routine maternal and newborn care in health facilities [18]. These are 1) the monitoring and management of labour using a partograph; 2) infection prevention for the mother; 3) active management of the third stage of labour; 4) thermal protection of the newborn; 5) immediate and exclusive breastfeeding; and 6) infection prevention for the newborn, including hygienic cord care. Each of these signal functions require a health facility to provide the appropriate staffing, supplies and 
commodities that are needed to perform it, and a health facility that is ready to perform all the signal functions can be regarded as having the means to offer a good standard of routine maternal and newborn care.

In this study our aim was threefold: we wished to apply signal function methodology to measure the readiness of health facilities to offer good quality routine maternal and newborn care in three settings where maternal/neonatal mortality were high and where facility delivery was being promoted. To do this we took representative samples of health facilities in each setting and conducted cross-sectional surveys to gather data on staffing, infrastructure and commodities that would be analysed as signal function components. We also wished to estimate the proportions of women who delivered in facilities that could be regarded as being ready to provide a good standard of routine care. To do this we used maternity registers at each sampled facility to count the number of women who had delivered in each one in the six months prior to the survey. Finally, we wanted to assess how and why the readiness of facilities to offer good quality routine care could change over time, and so we conducted the surveys twice at two time-points and compared them.

\section{Methods}

\section{Study settings and data collection methods}

This study was conducted within the context of the IDEAS project [19], which aimed to generate evidence to improve maternal and newborn health in Ethiopia, the Indian State of Uttar Pradesh, and Gombe State in North-Eastern Nigeria. In 2008 the Maternal Mortality Ratio (MMR) in Gombe State was estimated by the Ministry of Health to be 1002 [20]; in 2010-12 in Uttar Pradesh it was estimated by the Indian Government to be 292 [21]; while in 2010 the MMR in Ethiopia was estimated to be 523 [22].

Representative samples of public sector primary health facilities were taken from each of these settings in 2012 and 2015. The samples were part of a larger programme of population-level multi-stage cluster surveys for which the designs and sampling strategies have been described in detail elsewhere [19]. In Ethiopia, representative samples of health facilities were taken from 56 districts (Woreda) in the Amhara Region, Oromia Region, Southern Nations, Nationalities and Peoples' Region and Tigray Region. In Uttar Pradesh, representative samples of facilities were taken from 51 blocks in the six districts of Hardoi, Jhansi, Sultanpur, Maharanjganj, CSM Nagar (renamed Amethi) and Raebareli. In Gombe State, representative samples of health facilities were taken from 10 of the 11 local government areas (excluding Gombe Town). The 2012 surveys were conducted in May/June in Ethiopia and Nigeria, and in November in Uttar
Pradesh. The 2015 surveys were conducted in March/ April in Ethiopia, May in Nigeria and November in Uttar Pradesh.

At each facility the most senior member of staff was interviewed by a trained member of the survey team. The interview was structured around a standardised questionnaire and responses were entered directly by the interviewer into hand-held electronic devices. Each survey recorded 1) details of staff employed; 2) an inventory, taken by the study interviewer, of infrastructure, equipment and supplies (commodities) that were available and functioning on the day of the survey; and 3) data from facility registers of all the deliveries that had taken place at the facility in the previous 6 months.

\section{Analytical methods}

The facilities included in the analysis were those that would be expected to provide basic obstetric and neonatal care in the community, as indicated by their function in the health service structure in each country. These were health centres (as opposed to health posts) in Ethiopia; primary and community health centres in Uttar Pradesh; and primary health facilities in Nigeria. Skilled Birth Attendants (SBAs) were defined according to country definitions at the time of the surveys and included doctors, registered nurses and assistant nurses/ midwives. A facility was considered to have an SBA available if at least one was present at the facility on the day of the survey; this was to reflect the reality for many women in labour who arrive at a health facility unannounced and in need of immediate support.

Of the six routine care signal functions previously described, four were selected that were most dependent upon facility staffing, infrastructure and commodities. These were: management of labour using a partograph; active management of the third stage of labour using prophylactic uterotonics; general infection control for the mother and newborn; and specific infection control for the newborn via clean cord care. Within each signal function a number of practical components were identified - the staffing, infrastructure and equipment/commodities that would be required for it to be performed. The readiness of a facility to perform a signal function was measured by the presence of these components; all the components within a signal function had to be available and functioning at a facility on the day of the survey in order for the facility to be classed as ready to perform that function. If a facility was ready to perform all four signal functions then it was regarded as being ready to offer a good standard of basic maternal and newborn care. The components required to perform each signal function are shown in Table 1.

At each sampled facility the number of deliveries which had taken place there in the six months prior to 
Table 1 Facility components to fulfil four signal functions for basic maternal and newborn care

\begin{tabular}{|c|c|}
\hline Signal function & Components \\
\hline \multirow[t]{7}{*}{ Management of labour using a partograph } & SBA present at health facility \\
\hline & Blood pressure machine \\
\hline & Foetal stethoscope \\
\hline & Thermometer \\
\hline & Blank partographs \\
\hline & Urine testing kit \\
\hline & Oxytocin or Ergometrin \\
\hline \multirow[t]{2}{*}{ Active Management of Third Stage of Labour (prophylactic uterotonics) } & SBA present at health facility \\
\hline & Oxytocin or Ergometrin \\
\hline \multirow[t]{5}{*}{ General infection prevention } & SBA present at health facility \\
\hline & Source of clean running water \\
\hline & Soap \\
\hline & Disposable gloves \\
\hline & Disinfectant \\
\hline \multirow[t]{3}{*}{ Newborn infection prevention (clean cord care) } & SBA present at health facility \\
\hline & Sterile cord cutter \\
\hline & Cord tie \\
\hline
\end{tabular}

the survey were recorded from the facility registers. These delivery data were then linked to the signal function variables and from this an estimate could be made of the proportion of women who delivered in facilities that were ready to provide good quality basic maternal and newborn care, out of all the deliveries that took place in the sampled facilities.

In each setting a point estimate and confidence interval were calculated for the proportion of facilities that were ready to perform each signal function in 2012 and in 2015. These estimates were compared using chisquared tests. For each year and setting the median number of deliveries was calculated, and variation between these estimates assessed using a non-parametric $\mathrm{k}$-sample test. To compare the volumes of deliveries in care-ready facilities between 2012 and 2015 the clustering of births within facilities was taken into account and a point estimate and confidence interval calculated for each setting in each year. Data were analysed using Stata 14 software (Statacorp USA).

\section{Results}

In 2012, 166 facilities were surveyed that offered care during labour and delivery: 81 in Ethiopia, 60 in Uttar Pradesh and 25 in Gombe State. Of these, 11 facilities (7\%) were excluded from the analysis because of missing data relating to presence of SBAs, availability of commodities or volume of deliveries. In 2015, a total of 305 similar facilities were surveyed: 78 in Ethiopia, 121 in Uttar Pradesh and 106 in Gombe State. Of these, 38 facilities (12\%) were excluded from the 2015 analysis due to missing data as described above. The same sampling frames were used in 2012 and 2015, and changes in the sample size between years reflected a change in stakeholders' priorities.

\section{Number of deliveries in sampled facilities}

In 2012 in Ethiopia, the 76 health facilities with complete data recorded 4439 deliveries in the six months prior to being surveyed, a median of 43 deliveries per facility (Inter-Quartile Range (IQR) 19-78, Table 2). In 2015 a total of 19,278 deliveries were recorded in 78 health facilities in the six months prior to survey, raising the median to 238 per facility (IQR $141-355, p$ value for difference in medians < 0.001). In 2012 in Uttar Pradesh, 22,235 deliveries in 56 facilities were recorded in the six months prior to the survey, a median of 269 deliveries (IQR 16-695) per facility. In 2015, 38,217 deliveries were recorded in 88 facilities in six months, a median of 289 per facility (IQR 6-797, $p$-value for difference in medians $=0.864$ ). In 2012 in Gombe State, 23 health facilities recorded a total of 1575 deliveries in the six months prior to the survey, with a median of 57 deliveries per facility (IQR 15-90). In 2015, 101 facilities recorded 7154 deliveries, with a median of 39 deliveries per facility in six months (IQR 9-85, $p$-value for difference in medians $=0.644$ ).

Presence of skilled birth attendants in sampled facilities At least one SBA was present in $93 \%$ of surveyed facilities in Ethiopia in 2012 (95\% Confidence Interval (CI) $85-97$ ) and 97\% in 2015 (95\% CI 90-99, $p=0.24$. Uttar 
Table 2 Characteristics of 2012 and 2015 health facility surveys in three study settings

\begin{tabular}{|c|c|c|c|c|c|c|}
\hline & \multicolumn{2}{|l|}{ ETHIOPIA } & \multicolumn{2}{|c|}{ UTTAR PRADESH, INDIA } & \multicolumn{2}{|c|}{ GOMBE STATE, NIGERIA } \\
\hline & 2012 & 2015 & 2012 & 2015 & 2012 & 2015 \\
\hline Total facilities surveyed & 81 & 78 & 60 & 121 & 25 & 106 \\
\hline Total with complete data ${ }^{1}$ and analysed & 76 & 78 & 56 & 88 & 23 & 101 \\
\hline Total deliveries in 6 months prior to survey & 4439 & 19,278 & 22,235 & 38,217 & 1575 & 7154 \\
\hline Median (IQR) deliveries per facility & $43(19-78)$ & $238(141-355)$ & $269(16-695)$ & $289(6-767)$ & $57(15-90)$ & $39(9-85)$ \\
\hline $\mathrm{p}$-value for change in deliveries over time ${ }^{2}$ & & $<0.001$ & & 0.864 & & 0.644 \\
\hline
\end{tabular}

1. Complete data on volume of deliveries, availability of commodities or number of staff present

2. nonparametric $\mathrm{k}$-sample test on the equality of medians $-\mathrm{X}^{2}$ with continuity correction

Pradesh had at least one SBA present in $96 \%$ of surveyed facilities in 2012 (95\% CI 86-99) and 90\% in 2015 (95\% CI $81-95, p=0.15)$. In Gombe State at least one SBA was present in $52 \%$ of surveyed facilities in 2012 (95\% CI $32-71$ ), falling to $21 \%$ in 2015 (95\% CI 14-30, $p=$ $0.003)$.

\section{Readiness to perform four routine-care signal functions in} sampled facilities

Tables 3, 4 and 5 show, for Ethiopia, Uttar Pradesh and Gombe State respectively, the 12 commodities that contributed towards the four signal functions, and the proportions of sampled facilities where these were available and operational. The availability of these commodities was then combined with the presence of SBAs to determine the readiness of each facility to perform each routine care signal function.

In Ethiopia, the readiness to perform signal functions remained stable or improved between 2012 and 2015. In 2015 , over $90 \%$ of sampled facilities had the required commodities for clean cord care and prophylactic uterotonics. Approximately half were ready to manage labour using a partograph; this showed the greatest improvement from 2012 when the proportion was 32\% (95\% CI 22-43). Approximately half of facilities could provide adequate infection control (for those that could not this was mainly due to inadequate supplies of clean running water). Overall the proportion of surveyed primary care

Table 3 Ethiopia: proportions of sampled facilities with SBA and commodities, 2012 \& 2015

\begin{tabular}{|c|c|c|c|}
\hline & 2012 & 2015 & \\
\hline & $\%(95 \% \mathrm{Cl})$ & $\%(95 \% \mathrm{Cl})$ & $P\left(X^{2}\right)$ \\
\hline \multicolumn{4}{|l|}{ Present at facility on day of survey } \\
\hline At least one Skilled Birth Attendant & $93(85-97)$ & 97 (90-99) & 0.235 \\
\hline Blood pressure machine & $93(85-97)$ & $99(91-100)$ & 0.093 \\
\hline Foetal stethoscope & $99(91-100)$ & $100(-)$ & 0.311 \\
\hline Thermometer & $88(79-94)$ & 95 (87-98) & 0.137 \\
\hline Blank partographs & $64(53-74)$ & $79(69-87)$ & 0.040 \\
\hline Urine testing kit & $49(38-60)$ & $73(62-82)$ & 0.002 \\
\hline Prophylactic uterotonics & $93(85-97)$ & 96 (89-99) & 0.448 \\
\hline Source of clean running water & $55(44-66)$ & $58(46-68)$ & 0.762 \\
\hline Soap & $76(65-85)$ & $92(84-97)$ & 0.007 \\
\hline Disposable gloves & $95(87-98)$ & $100(-)$ & 0.040 \\
\hline Disinfectant & $78(67-86)$ & $94(85-97)$ & 0.005 \\
\hline Sterile cord cutter & $100(-)$ & $99(91-100)$ & 0.324 \\
\hline Cord tie & $92(83-96)$ & $100(-)$ & 0.011 \\
\hline \multicolumn{4}{|l|}{ Readiness to perform signal functions } \\
\hline Management of labour using partograph & $32(22-43)$ & $55(44-66)$ & 0.004 \\
\hline Prophylactic uterotonics & $88(79-94)$ & $95(87-98)$ & 0.137 \\
\hline Infection control & $43(33-55)$ & $51(40-62)$ & 0.332 \\
\hline Clean cord care & $85(76-92)$ & 96 (89-99) & 0.024 \\
\hline All signal functions & $22(14-33)$ & $35(25-46)$ & 0.096 \\
\hline
\end{tabular}


Table 4 Uttar Pradesh: proportions of sampled facilities with SBA and commodities, 2012 \& 2015

\begin{tabular}{|c|c|c|c|}
\hline & 2012 & 2015 & \multirow{2}{*}{$\begin{array}{l}P \\
\left(X^{2}\right)\end{array}$} \\
\hline & $\%(95 \% \mathrm{Cl})$ & $\%(95 \% \mathrm{Cl})$ & \\
\hline \multicolumn{4}{|l|}{ Present at facility on day of survey } \\
\hline At least one Skilled Birth Attendant & $96(86-99)$ & $90(81-95)$ & 0.146 \\
\hline Blood pressure machine & $98(88-100)$ & 97 (90-99) & 0.566 \\
\hline Foetal stethoscope & $52(39-65)$ & $53(43-64)$ & 0.850 \\
\hline Thermometer & $96(87-99)$ & $95(88-98)$ & 0.777 \\
\hline Blank partographs & $18(10-30)$ & $36(27-47)$ & 0.019 \\
\hline Urine testing kit & $38(26-51)$ & $61(51-71)$ & 0.006 \\
\hline Prophylactic uterotonics & $45(32-58)$ & $66(55-75)$ & 0.013 \\
\hline Source of clean running water & $84(72-91)$ & $92(84-96)$ & 0.134 \\
\hline Soap & 96 (87-99) & $92(84-96)$ & 0.293 \\
\hline Disposable gloves & $91(80-96)$ & $89(80-94)$ & 0.643 \\
\hline Disinfectant & 95 (84-98) & $91(83-95)$ & 0.414 \\
\hline Sterile cord cutter & $96(87-99)$ & $86(77-92)$ & 0.050 \\
\hline Cord tie & $77(64-86)$ & $76(66-84)$ & 0.929 \\
\hline \multicolumn{4}{|l|}{ Readiness to perform signal functions } \\
\hline Management of labour using partograph & $2(0 \cdot 2-12)$ & $23(15-33)$ & 0.001 \\
\hline Prophylactic uterotonics & $43(31-56)$ & $64(53-73)$ & 0.016 \\
\hline Infection control & $73(60-83)$ & $74(64-82)$ & 0.932 \\
\hline Clean cord care & $71(58-82)$ & $72(61-80)$ & 0.983 \\
\hline All signal functions & $2(0 \cdot 2-12)$ & $23(15-35)$ & 0.001 \\
\hline
\end{tabular}

Table 5 Gombe State: proportions of sampled facilities with SBA and commodities, 2012 \& 2015

\begin{tabular}{|c|c|c|c|}
\hline & 2012 & 2015 & $P\left(X^{2}\right)$ \\
\hline & $\%(95 \% \mathrm{Cl})$ & $\%(95 \% \mathrm{Cl})$ & \\
\hline \multicolumn{4}{|l|}{ Present at facility on day of survey } \\
\hline At least one Skilled Birth Attendant & $52(32-71)$ & $21(14-30)$ & 0.003 \\
\hline Blood pressure machine & $87(66-96)$ & $92(85-96)$ & 0.439 \\
\hline Foetal stethoscope & $100(-)$ & $90(82-95)$ & 0.110 \\
\hline Thermometer & $87(66-96)$ & $72(63-80)$ & 0.147 \\
\hline Blank partographs & $26(12-48)$ & $7(3-14)$ & 0.008 \\
\hline Urine testing kit & $65(44-82)$ & $47(37-56)$ & 0.110 \\
\hline Prophylactic uterotonics & $70(48-85)$ & $73(64-81)$ & 0.721 \\
\hline Source of clean running water & $74(52-88)$ & $37(28-47)$ & 0.002 \\
\hline Soap & $87(66-96)$ & $77(68-84)$ & 0.305 \\
\hline Disposable gloves & $83(61-94)$ & $93(86-97)$ & 0.115 \\
\hline Disinfectant & $91(71-98)$ & $73(64-81)$ & 0.069 \\
\hline Sterile cord cutter & $87(66-96)$ & $92(85-96)$ & 0.439 \\
\hline Cord tie & $78(57-91)$ & $74(65-82)$ & 0.691 \\
\hline \multicolumn{4}{|l|}{ Readiness to perform signal functions } \\
\hline Management of labour using partograph & $17(7-39)$ & $2(0.5-8)$ & 0.002 \\
\hline Prophylactic uterotonics & $39(22-60)$ & $17(11-26)$ & 0.020 \\
\hline Infection control & $39(22-60)$ & $7(3-14)$ & $<0.001$ \\
\hline Clean cord care & $43(25-64)$ & $15(9-23)$ & 0.003 \\
\hline All signal functions & $17(7-39)$ & 0 & $<0.001$ \\
\hline
\end{tabular}


facilities in Ethiopia which were ready to perform all four routine care signal functions increased from $22 \%$ (95\% CI 14-33) in 2012 to 35\% (95\% CI 25-46) in 2015.

In Uttar Pradesh the availability of commodities also remained stable or improved between 2012 and 2015. In both years approximately three-quarters of surveyed facilities were ready to provide basic infection control and clean cord care. In 2015, only around one quarter were ready to manage labour using a partograph but this had increased substantially from 2012 due to increased availability of blank partographs and urine testing kits. In 2015, two-thirds had prophylactic uterotonics available. Overall, the proportion of primary facilities in Uttar Pradesh which were ready to perform the four routine care signal functions increased from $2 \%(95 \%$ CI $0.2-12)$ in 2012 to $23 \%$ (95\% CI 15-35) in 2015.

In Gombe State, the picture was reversed. The availability of most commodities in health facilities fell between 2012 and 2015. The proportion of facilities with a supply of clean running water decreased from $74 \%$ (95\% CI 52-88) in 2012 to $37 \%$ (95\% CI 28-47) in 2015. These declines mirrored the fall in the proportion of facilities with an SBA present on the day of the survey and meant that no facilities were ready to perform all four signal functions in 2015, a fall from $17 \%$ (95\% CI 7-39) in 2012.

\section{Proportions of women delivering in facilities ready to perform routine care signal functions}

Figures 1, 2 and 3 show, for each setting in 2012 and 2015 , the proportion of all deliveries at sampled facilities in the six months prior to the surveys that took place in facilities ready to perform each signal function. In Ethiopia in 2012, 40\% (95\% CI 26-57) of primary facility deliveries in the six months prior to the survey took place in facilities that were ready to perform all four basic care signal functions at the time of the survey. This proportion was $43 \%$ (95\% CI 31-56) in 2015. In Uttar Pradesh, the proportions of deliveries in primary facilities that were ready to perform all four signal functions were $4 \%$ (95\% CI $0.6-24)$ in 2012 and 39\% (95\% CI $26-$ 55 ) in 2015. In Gombe State, $25 \%$ (95\% CI 6-66) of primary facility deliveries took place in facilities that were ready to perform all four signal functions, but by 2015 no women gave birth in a facility which was ready to perform all four functions at the time of the survey. Taken together, 64,649 deliveries were recorded in our three-country sample of primary care facilities in 2015 , but just 23,425 (36\%, 95\% CI 27-47) occurred in facilities that could be considered ready to offer good quality routine maternal and newborn care.

\section{Discussion}

This study of the quality of routine obstetric and newborn care in health facilities in three settings with high maternal mortality revealed that between 2012 and 2015 the proportion of facilities that were ready to offer such care showed some increase in Ethiopia, a more substantial increase in the Indian state of Uttar Pradesh, but a decrease in Gombe State in Nigeria. After incorporating the number of women delivering in these facilities we observed that across these settings no more than 4 out of every 10 women who delivered in a sampled facility in 2015 gave birth in a setting with the staffing, infrastructure and commodities needed to provide basic maternal and newborn care.

In Ethiopia and the state of Uttar Pradesh the increased readiness to provide basic care were not driven by a greater presence of SBAs, which was consistently high, but rather by improved availability of simple

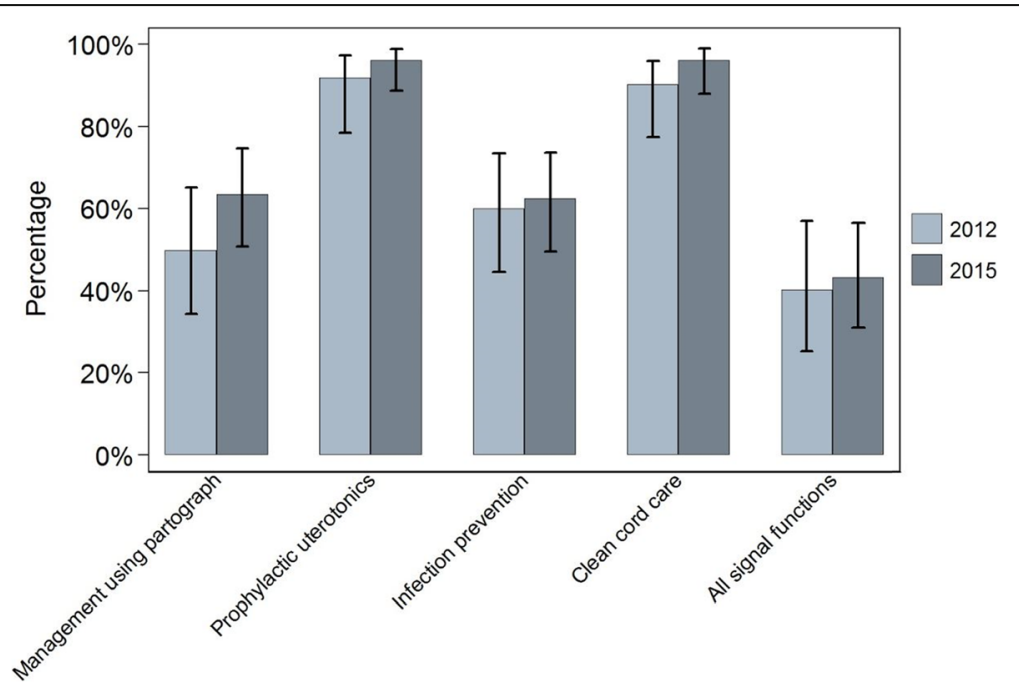

Fig. 1 Ethiopia - proportion of all deliveries in facilities offering routine care signal functions 


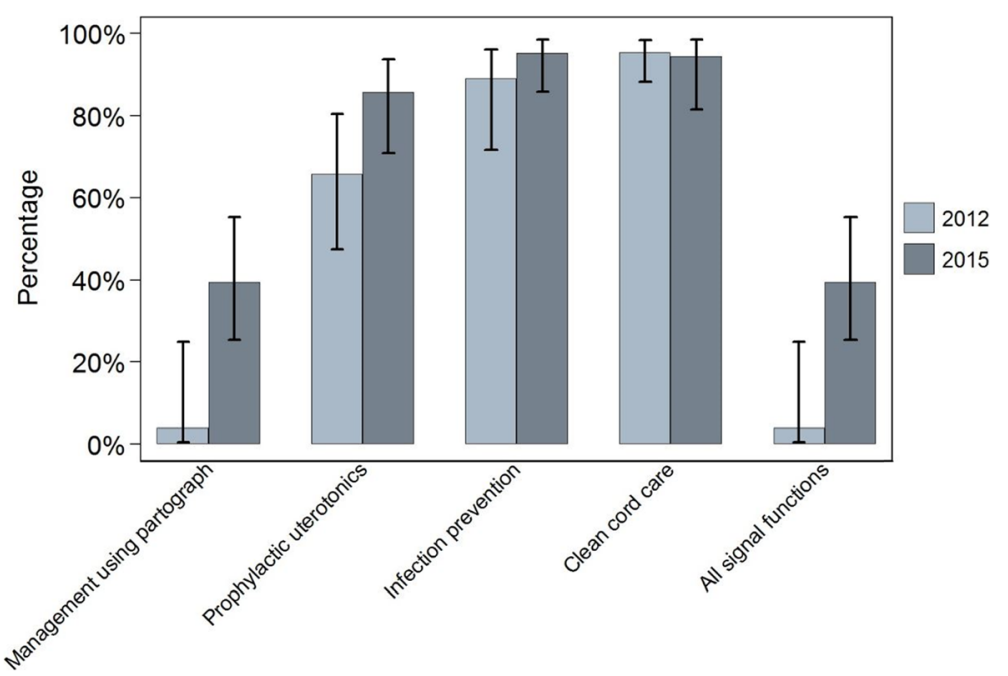

Fig. 2 Uttar Pradesh - proportion of all deliveries in facilities offering routine care signal functions

commodities such as partographs, urine testing kits and prophylactic uterotonics. In both settings this increased the proportion of facilities that were ready to perform all four of the signal functions used to measure routine maternal and newborn care. As a result, between 2012 and 2015 the proportion of facility births that took place in these more prepared facilities showed some increase in Ethiopia and a more substantial increase in Uttar Pradesh.

The facilities we surveyed in Ethiopia also experienced a substantial increase in the volume of deliveries between 2012 and 2015, reflecting government-led initiatives to promote facility births [23]. There was little increase in the median number of deliveries at sampled facilities between 2012 and 2015 in Uttar Pradesh, where a central government incentive to encourage facility births - in the form of a conditional cash-transfer scheme - had been in place since 2005 [24]. This initiative is thought to have led to significant increases in facility deliveries in public facilities across India between 2005 and 2010 [25] with one evaluation estimating that, in Uttar Pradesh, the proportion of such deliveries increased from 17 to $47 \%$ between 2005 and 2008 [26]. Our study suggests that by 2012 the impact of this intervention in Uttar Pradesh may have attenuated.

Despite these improvements in Ethiopia and Uttar Pradesh, by 2015 there remained a number of missed opportunities in these settings to provide routine but potentially life-saving care in childbirth. In Ethiopia in 2015 approximately $43 \%$ of women who gave birth in sampled facilities in the six months prior to survey did so in facilities that were ready to perform all four routine

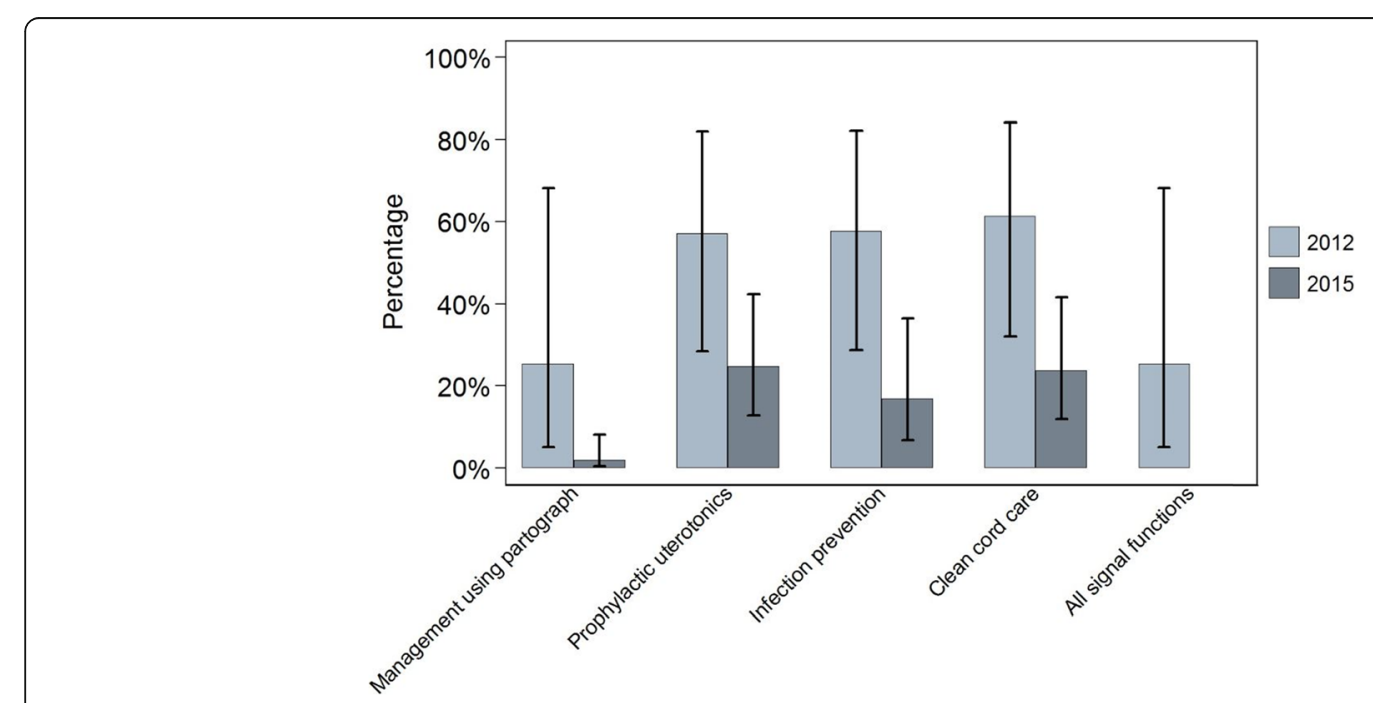

Fig. 3 Gombe State - proportion of all deliveries in facilities offering routine care signal functions 
care signal functions. In Uttar Pradesh the equivalent proportion was $39 \%$.

In Gombe State, the proportions of primary facilities that were ready to perform all four routine care signal functions declined from approximately $25 \%$ in 2012 to $0 \%$ in 2015. Part of this change was due to a steep decline in the proportion of facilities that had an SBA present on the day of the survey. Difficulties in recruiting and retaining skilled midwives in North-Eastern Nigeria [27] were exacerbated by repeated health worker strikes across the country [28]. In addition, NorthEastern Nigeria had been subject to severe political instability since 2009 and, while this primarily affected states to the north and east of Gombe, an estimated 900, 000 people had been internally displaced across the region by January 2015 [29]. It is plausible that this had placed further pressure upon the recruitment and retention of skilled medical personnel, and also influenced the capability of pregnant women to seek a facility delivery.

Insufficient supplies of essential commodities contributed to reduced facility readiness in all three settings, a finding that reflects the inability of many primary facilities in resource-poor settings to provide the most essential care, and which has been reflected in other subSaharan African countries [30]. Such has been the scale of this problem with regard to commodities that in 2012 the UN Commission on Life-Saving Commodities for Women and Children (UNColSC) was established [31, 32]. This aimed to address problems in the supply of key commodities in maternal and newborn health across 50 of the poorest countries. While the UNColSC focussed attention on different commodities to those assessed in this study (with the exception of the uterotonic oxytocin), its report identified a complex set of barriers that would apply to a broader range of equipment and supplies. These included weak regulatory bodies, insufficient returns on manufacturing investment, breakdowns in distribution, low demand and incorrect prescription or use of medicines [31]. In 2015 an evaluation of progress towards the Commission's goals in 12 countries (of which Ethiopia and Nigeria were two) found that an average of $40 \%$ of facilities faced stock-outs of commodities and that persistent "bottlenecks" in supplies existed at country level [32].

The life-saving potential of good quality care at the time of birth is recognised as having an important impact upon the desire of women to deliver in health facilities. In a study in northern Uganda, a fully supplied health facility was shown to be the most important enabling factor for women to choose a facility birth, ahead of increased access and improved treatment by health workers [33]. Absent or poorly functioning equipment can also cause facility staff to feel incapable of providing adequate care despite their best efforts, which can have a damaging impact upon staff morale [34].

Developing methods that can appropriately reflect the quality of care available to service users, and produce actionable evidence without adding burden to countries, is an urgent priority. In this analysis we measured, via the signal function methodology, the capability of health facilities to provide a good standard of routine maternal and newborn care, but we did not measure the actual care that was delivered in practice. This is a limitation, and the inclusion of data on SBA behaviours and processes could have been even more revealing. However, a considerable strength of this study was the application of readily available data on the quality of health facility care to the denominator of the number of deliveries taking place in those facilities, in order to estimate the proportion of women who had access to potentially lifesaving care. This methodological approach responds to a call to action by the global measurement community [35-38], has the potential to be integrated within routine data systems, is relatively low cost and is highly temporal. The use of a composite measure provides a useful summary of facility capability, while breaking down the components of each one makes it easier for health facility programmes to identify where to act.

The evidence presented here is not at the population level, since it refers only to women delivering in government owned primary-care facilities. Furthermore, applying cross-sectional input data to births recorded in facility registers during the previous six months does assume that facility inputs were relatively static, which may have led to an over- or under-estimation of results (depending on stock-out patterns). But, since the same methods were applied at each time and setting, the comparison between levels remains valid and the need for action clearly identified.

\section{Conclusion}

Primary facilities in all three settings had sub-optimal inputs available for basic maternal and newborn care. Incorporating the volume of births per facility revealed that the majority of women who delivered in a primary health facility did not find the routine care that they may have expected or hoped for. This simple and affordable method for measuring this dimension of quality can help to reveal where and what action is needed to realise the potential of the primary health system to save more maternal and newborn lives.

\section{Abbreviations}

SBA: Skilled Birth Attendant; MMR: Maternal Mortality Ratio; IQR: Inter-Quartile Range; Cl: Confidence Interval; UNColSC: United Nations Commission on LifeSaving Commodities for Women and Children 


\section{Acknowledgements}

We thank all of the health facility staff who participated in the health facility surveys. We also thank our Monitoring and Evaluation Partners in each setting for the practical implementation of the surveys. These were JaRco Consulting in Ethiopia, Sambodhi Research and Communications in India, and, in Gombe State, Health Hub in 2012 and Data Research and Mapping Consult Ltd. in 2015.

\section{Authors' contributions}

TM designed the surveys, oversaw their implementation, and conceived the statistical analysis. KT provided programming and data management support for the surveys, carried out the statistical analyses, wrote the first draft of the manuscript, made the tables and figures and curated the data. DB, MG and NU coordinated the survey implementation in Ethiopia, Uttar Pradesh and Gombe State respectively, and contributed to country data interpretation. JS contributed to study design. DW provided information specialist support. All authors critically reviewed the manuscript, provided important intellectual input, approved the final version and agreed to be accountable for their contributions. Deepthi Wickremasinghe sadly died on 2nd April 2020, shortly prior to publication of this article. Her wisdom, kindness and dedication to improving maternal and newborn health are greatly missed.

\section{Funding}

The research was supported by IDEAS - Informed Decisions for Actions to improve maternal and newborn health (http://ideas.lshtm.ac.uk), which is funded through a grant from the Bill \& Melinda Gates Foundation to the London School of Hygiene \& Tropical Medicine. The funder had no role in the study design, data collection, data analysis, data interpretation, or preparation of the manuscript.

\section{Availability of data and materials}

The survey questionnaires and resulting pooled dataset which formed the basis of this study are available from the LSHTM data repository (Data Compass). The dataset and instruments for Ethiopia can be found at https:// doi.org/10.17037/DATA.129; for Uttar Pradesh they are at https://doi.org/10. 17037/DATA.113; and for Gombe State they are at https://doi.org/10.17037/ DATA.131

\section{Ethics approval and consent to participate}

Ethical approvals were obtained at national and regional levels from the three countries in which data were collected. In Ethiopia, national ethical approval was obtained from the Ministry of Science and Technology of the Federal Democratic Republic of Ethiopia, and regional ethical approvals were obtained from the Amhara Regional Health Bureau, the Oromia Regional Health Bureau and the Tigray Regional Health Bureau. In Uttar Pradesh, ethical approval was obtained from the Ethical Review Board of the Society for the Promotion of Ethical Clinical Trials (SPECT-ERB), and from the National Rural Health Mission in Uttar Pradesh. In Nigeria, national ethical approval was obtained from the National Health Research Ethics Committee of the Federal Ministry of Health in Abuja, and state approval was obtained from the Gombe State Ministry of Health in Gombe. Ethical approval for the surveys was also obtained from the London School of Hygiene and Tropical Medicine (reference 6008).

All survey respondents provided informed, voluntary written consent to be interviewed.

\section{Consent for publication}

Not applicable.

\section{Competing interests}

All authors declare no conflict of interests.

\section{Author details}

${ }^{1}$ Faculty of Epidemiology and Population Health, London School of Hygiene \& Tropical Medicine, Keppel Street, London WC1E 7HT, UK. ${ }^{2}$ Faculty of Infectious and Tropical Diseases, London School of Hygiene \& Tropical Medicine, Keppel Street, London WC1E 7HT, UK. ${ }^{3}$ Faculty of Public Health and Policy, London School of Hygiene \& Tropical Medicine, 15-17 Tavistock Place, London WC1H 9SH, UK.
Received: 26 September 2019 Accepted: 7 April 2020

Published online: 12 May 2020

\section{References}

1. World Health Organization, UNICEF, UNFPA, World Bank and UNPD. Trends in maternal mortality: 1990 to 2015: estimates by WHO, UNICEF, UNFPA, World Bank Group and the United Nations Population Division. Geneva; World Health Organization: 2015.

2. United Nations Inter-agency Group for Child Mortality Estimation (UN IGME), 'Levels \& Trends in Child Mortality: Report 2018, Estimates developed by the United Nations Inter-agency Group for Child Mortality Estimation', United Nations Children's Fund, New York, 2018.

3. Campbell OM, Graham WJ. Lancet maternal survival series steering g: strategies for reducing maternal mortality: getting on with what works. Lancet. 2006;368(9543):1284-99.

4. Kruk ME, Gage AD, Arsenault C, Jordan K, Leslie HH, Roder-DeWan S, Adeyi O, Barker P, Daelmans B, Doubova SV, et al. High-quality health systems in the sustainable development goals era: time for a revolution. Lancet Glob Health. 2018;6(11):e1196-252.

5. World Health Organization. Reduction of maternal mortality : a joint WHO/ UNFPA/UNICEF/World Bank statement. Geneva: World Health Organization; 1999.

6. World Health Organization, International Confederation of Midwives, Fédération internationale de Gynécologie et d'Obstétrique. Making pregnancy safer : the critical role of the skilled attendant : a joint statement by WHO, ICM and FIGO. Geneva: World Health Organization; 2004.

7. Global Strategy for Women's, Children's and Adolescents' Health (2016-2030). New York: Every Woman Every Child; 2015.

8. Gabrysch S, Campbell OM. Still too far to walk: literature review of the determinants of delivery service use. BMC Pregnancy Childbirth. 2009:9:34.

9. UNICEF Data: Delivery Care 2018, https://data.unicef.org/topic/maternalhealth/delivery-care/, accessed on 14/07/2019.

10. Alkema L, Chou D, Hogan D, Zhang S, Moller AB, Gemmill A, Fat DM, Boerma T, Temmerman M, Mathers $C$, et al. Global, regional, and national levels and trends in maternal mortality between 1990 and 2015, with scenario-based projections to 2030: a systematic analysis by the UN maternal mortality estimation inter-agency group. Lancet. 2016;387(10017): 462-74.

11. Fink G, Ross R, Hill K. Institutional deliveries weakly associated with improved neonatal survival in developing countries: evidence from 192 demographic and health surveys. Int J Epidemiol. 2015;44(6):1879-88.

12. Holmer H, Oyerinde K, Meara JG, Gillies R, Liljestrand J, Hagander L. The global met need for emergency obstetric care: a systematic review. BJOG. 2015;122(2):183-9.

13. Scott S, Ronsmans $C$. The relationship between birth with a health professional and maternal mortality in observational studies: a review of the literature. Tropical Med Int Health. 2009;14(12):1523-33.

14. Souza JP, Gulmezoglu AM, Vogel J, Carroli G, Lumbiganon P, Qureshi Z, Costa MJ, Fawole B, Mugerwa Y, Nafiou I, et al. Moving beyond essential interventions for reduction of maternal mortality (the WHO multicountry survey on maternal and newborn health): a cross-sectional study. Lancet. 2013;381(9879):1747-55.

15. van den Broek NR, Graham WJ. Quality of care for maternal and newborn health: the neglected agenda. BJOG. 2009;116(Suppl 1):18-21.

16. World Health Organization. Standards for improving quality of maternal and newborn care in health facilities. Geneva; Switzerland. 2016.

17. World Health Organisation, Unicef, AMDD: Monitoring emergency obstetric care: a handbook. Geneva; Switzerland. 2009.

18. Gabrysch S, Civitelli G, Edmond KM, Mathai M, Ali M, Bhutta ZA, Campbell OM. New signal functions to measure the ability of health facilities to provide routine and emergency newborn care. PLoS Med. 2012;9(11): e1001340.

19. Darmstadt GL, Marchant T, Claeson M, Brown W, Morris S, Donnay F, Taylor M, Ferguson R, Voller S, Teela KC, et al. A strategy for reducing maternal and newborn deaths by 2015 and beyond. BMC Pregnancy Childbirth. 2013;13:216.

20. Gombe State Government: Strategic Health Development Plan (2010 2015). Gombe State Ministry of Health, March 2010.

21. Government of India; National Portal of India; Maternal Mortality Ratio (MMR) per 100000 live births; http://niti.gov.in/content/maternal-mortalityratio-mmr-100000-live-births. 
22. WHO, UNICEF, UNFPA, World Bank Group and the United Nations Population Division; Internationally comparable MMR estimates by the Maternal Mortality Estimation Inter-Agency Group (MMEIG); Maternal mortality in 2000-2017: Ethiopia; https://www.who.int/gho/maternal_health/ countries/eth.pdf.

23. Berhanu DA, B.I.: Community Based Newborn Care Programme in Ethiopia 2013-2017: Final Evaluation Report; IDEAS, London School of Hygiene \& Tropical Medicine. 2019.

24. Government of India; Ministry of Health and Family Welfare; Maternal Health Division, New Delhi; Janani Suraksha Yojana. https://nhm.gov.in/ index . php?lang=1\&level=3\&lid=309\&sublinkid=841.

25. Lim SS, Dandona L, Hoisington JA, James SL, Hogan MC, Gakidou E. India's Janani Suraksha Yojana, a conditional cash transfer programme to increase births in health facilities: an impact evaluation. Lancet. 2010;375(9730):2009-23.

26. United Nations Population Fund, India (UNPFA); Concurrent Assessment of Janani Suraksha Yojana (JSY) in Selected States; 2009.

27. Salami B, Dada FO, Adelakun FE. Human resources for health challenges in Nigeria and nurse migration. Policy Polit Nurs Pract. 2016;17(2):76-84.

28. Oleribe OO, Ezieme IP, Oladipo O, Akinola EP, Udofia D, Taylor-Robinson SD Industrial action by healthcare workers in Nigeria in 2013-2015: an inquiry into causes, consequences and control-a cross-sectional descriptive study. Hum Resour Health. 2016;14(1):46.

29. OCHA. Nigeria : 2018 People on need of humanitarian aid. https://reliefweb. int/report/nigeria/nigeria-northeast-crisis-situation-report-no-1-30-january2015, accessed 15/07/2019.

30. Kruk ME, Leslie HH, Verguet S, Mbaruku GM, Adanu RM, Langer A. Quality of basic maternal care functions in health facilities of five African countries: an analysis of national health system surveys. Lancet Glob Health. 2016;4(11): e845-55.

31. UN Commission on Life-Saving Commodities for Women and Children, 2012, http://www.unfpa.org/publications/un-commission-life-savingcommodities-women-and-children, accessed on 28/08/2016.

32. Pronyk PM, Nemser B, Maliqi B, Springstubb N, Sera D, Karimov R, Katwan E, Walter B, Bijleveld P, Teams UNTR, et al. The UN Commission on life saving commodities 3 years on: global progress update and results of a multicountry assessment. Lancet Glob Health. 2016;4(4):e276-86.

33. Anastasi E, Borchert M, Campbell OM, Sondorp E, Kaducu F, Hill O, Okeng D, Odong VN, Lange IL. Losing women along the path to safe motherhood: why is there such a gap between women's use of antenatal care and skilled birth attendance? A mixed methods study in northern Uganda. BMC Pregnancy Childbirth. 2015;15:287.

34. Penfold S, Shamba D, Hanson C, Jaribu J, Manzi F, Marchant T, Tanner M, Ramsey K, Schellenberg D, Schellenberg JA. Staff experiences of providing maternity services in rural southern Tanzania - a focus on equipment, drug and supply issues. BMC Health Serv Res. 2013;13:61.

35. Do M, Micah A, Brondi L, Campbell H, Marchant T, Eisele T, Munos M. Linking household and facility data for better coverage measures in reproductive, maternal, newborn, and child health care: systematic review. J Glob Health. 2016;6(2):020501.

36. Grove J, Claeson M, Bryce J, Amouzou A, Boerma T, Waiswa P, Victora C, Kirkland G. Maternal, newborn, and child health and the sustainable development goals--a call for sustained and improved measurement. Lancet. 2015;386(10003):1511-4.

37. Marchant T, Bryce J, Victora C, Moran AC, Claeson M, Requejo J, Amouzou A, Walker N, Boerma T, Grove J. Improved measurement for mothers, newborns and children in the era of the sustainable development goals. J Glob Health. 2016;6(1):010506.

38. Munos MK, Stanton CK, Bryce J. Core Group for improving coverage measurement for $\mathrm{M}$ : improving coverage measurement for reproductive, maternal, neonatal and child health: gaps and opportunities. J Glob Health. 2017;7(1):010801.

\section{Publisher's Note}

Springer Nature remains neutral with regard to jurisdictional claims in published maps and institutional affiliations.

Ready to submit your research? Choose BMC and benefit from:

- fast, convenient online submission

- thorough peer review by experienced researchers in your field

- rapid publication on acceptance

- support for research data, including large and complex data types

- gold Open Access which fosters wider collaboration and increased citations

- maximum visibility for your research: over $100 \mathrm{M}$ website views per year

At BMC, research is always in progress.

Learn more biomedcentral.com/submissions 